\title{
ASPECTOS GERAIS DO PROGRAMA DE USO PÚBLICO DO PARQUE ESTADUAL DE CAMPOS DO JORDÃO-SP'
}

\author{
Heros Augusto Santos Lobo ${ }^{2}$
}

\section{Resumo}

Os Parques são uma categoria de Unidade de Conservação que permite Uso Público para fins turísticos. Este uso é preconizado na forma de ecoturismo, sendo também compreendido, por uma questão do enfoque adotado, como turismo sustentável. O Parque Estadual de Campos do Jordão está entre as mais visitadas Unidades de Conservação com controle de acesso do Estado de São Paulo. Todavia, a maioria das atividades e serviços disponíveis para o público, bem como perfil predominante de visitação, não se assemelham aos preceitos de ecoturismo e turismo sustentável. Assim, realizou-se a análise de um diagnóstico para o uso público do Parque, o qual resultou em uma matriz estratégica para a gestão. As principais forças impulsoras identificadas para o uso público foram a ausência de grandes conflitos entre os atores envolvidos, a visibilidade e acessibilidade do Parque e seu elevado número de visitantes. As forças contrárias mais evidentes foram a deficiência de infraestrutura, de recursos humanos e o perfil do público, aparentemente pouco interessado pelas possibilidades de roteiros ecoturísticos no Parque. Com isso, desenvolveu-se um Programa de Uso Público baseado em diretrizes, objetivos, indicadores e linhas de ação, cujo enfoque central considerou cinco aspectos principais: infraestrutura de visitação e divulgação; manejo de trilhas; recursos humanos; gestão da visitação e envolvimento da comunidade local. As conclusões ressaltam a necessidade de que o Programa de Uso Público - bem como todo o Plano de Manejo elaborado - seja implantado, de forma a se tornar uma ferramenta prática para a gestão, não uma orientação teórica ou mesmo o cumprimento de uma obrigatoriedade legal.

Palavras-chave: Áreas Naturais Protegidas; Ecoturismo; Uso Público; Plano de Manejo.

\begin{abstract}
Parks in Brazil are a category of natural protected area (NPA) where the tourism is allowed. Tourism in Parks is conceptualized as Ecotourism, and considering the adopted focus, is also understood as Sustainable Tourism. Campos do Jordão State Park is one of the most visited NPAs with controlled access in São Paulo State (up to 100,000 visitors per year). However, most of activities and tourist services, as well as the visitor's profile, are not connected to Ecotourism or Sustainable Tourism concepts. Based on this, an analysis of the "public use

\footnotetext{
${ }^{1} \mathrm{O}$ presente texto foi elaborado com base no Programa de Uso Público, Subprograma de Visitação Pública, proposto no Plano de Manejo do Parque Estadual de Campos de Jordão (PECJ), em sua versão de 2013, o qual foi elaborado pelo mesmo autor.

${ }^{2}$ Bacharel em Turismo. Especialista em Gestão e Manejo Ambiental em Sistemas Florestais. Mestre em Geografia. Doutor em Geociências e Meio Ambiente. Docente da Universidade Federal de São Carlos, Campus Sorocaba, Depto. de Geografia, Turismo e Humanidades. E-mail: heroslobo@ufscar.br
} 
diagnosis" was made, resulting in a strategic matrix for management. The main driving forces detected were the absence of conflicts between stakeholders, the positive reputation, the accessibility and the high number of visitors. The most evident opposite forces were the poor infrastructures, gaps in human resources and the profile of visitors, which are apparently uninterested in ecotourism in the Park. Based on this, the Program of Public Use was developed with guidelines, objectives, indicators and action lines, that are focused in five main aspects: visitation infrastructure and merchandising; management of trails; human resources; management of visitors and envelopment of local communities. The conclusions highlight the needs of practical implantation of the Program of Public Use and the Management Plan as a whole, converting this document in a practical tool for management, instead of a theoretical orientation or, even worst, just the fulfillment of an obligation.

Keywords: Natural protected areas; Ecotourism; Public Use; Management Plan.

\section{INTRODUÇÃO}

As Unidades de Conservação (UC) são áreas protegidas previstas em lei no Brasil, tendo sido sintetizadas e consolidadas por meio do Sistema Nacional de Unidades de Conservação (SNUC), uma lei federal do ano 2000 que apresenta as categorias de UC que podem ser criadas em território nacional. Estas se dividem em dois grupos, as de uso sustentável e as de preservação integral. Em linhas gerais, a diferença maior entre estes dois grupos está nas possibilidades de interferência antrópica aceitas em cada uma das categorias de UC que elas englobam, sendo as UCs de Preservação Integral aquelas de uso mais restritivo e, portanto, mais focadas na preservação e conservação dos recursos naturais. Os Parques (Nacionais, Estaduais, Municipais Naturais) são áreas naturais protegidas de domínio público que objetivam a preservação de ecossistemas naturais de grande relevância ecológica e beleza cênica e possibilidades de uso público, o qual deve ser regido pelo plano de manejo da Unidade de Conservação e normas complementares do órgão gestor (BRASIL, 2000). As formas de uso público permitidas nas UCs de proteção integral variam em sua terminologia, mas em sua essência, remetem à pesquisa, à educação e interpretação ambiental, à recreação em áreas naturais e ao ecoturismo.

O ecoturismo é um segmento do mercado de turismo que tem como base os recursos naturais para sua execução, sendo compreendido por alguns autores (e.g. FENNEL, 2003) como um modo alternativo ao turismo de massa. Eagles et al. (2002) comentam sobre a perspectiva do ecoturismo em áreas naturais protegidas no mundo, ressaltando sua aproximação cada vez maior do ideário de Turismo Sustentável. No Brasil, verifica-se tendência semelhante, inicialmente anunciada pela definição de ecoturismo mais usada no país, publicada por Brasil (1994) e repetida em diversos diplomas públicos e trabalhos acadêmicos. Em um parágrafo e de forma sintética, a definição em questão aborda o uso sustentável do patrimônio natural e cultural, o incentivo à sua conservação e à conscientização sobre temas ambientais, e ainda gerando bem estar nas populações provavelmente, aquelas envolvidas com a atividade. No âmbito prático esta anexação ao Turismo Sustentável também pode ser vista, tomando como exemplo o caso do destino 
Bonito, no Mato Grosso do Sul. Trata-se de um tradicional destino de ecoturismo nacional, mas que cada vez mais vem se posicionando como destino de Turismo Sustentável, alcançando, inclusive, premiações internacionais sobre o tema.

Inserido neste contexto legal e conceitual, o Parque Estadual de Campos do Jordão (PECJ) foi criado em 27 de março de 1941, por meio do Decreto Estadual no 11.908. Sua área total é de 8.341 ha, abrangendo $1 / 3$ da superfície territorial do município de Campos do Jordão. O município se localiza a $185 \mathrm{~km}$ da capital do Estado e a 345 da cidade do Rio de Janeiro, na região do vale do Paraíba.

O município de Campos do Jordão é um renomado e consolidado destino turístico do Estado de São Paulo, tendo na natureza o seu principal fator de atração, especificamente o clima. No entanto, ele destoa da maioria dos atrativos nacionais em que o clima é fator preponderante de atração. Na maioria dos casos, o país que possui um os mais extensos litorais do mundo, se faz lembrar no Turismo em função do calor de seu verão tropical. Mas no caso específico de Campos do Jordão, as suas elevadas altitudes, que se aproximam da escala dos $2.000 \mathrm{~m}$, aliadas à sua posição específica no território nacional, condicionam um clima ameno o ano todo, com invernos mais acentuados. De acordo com dados do Centro Integrado de Informações Agrometeorológicas (CIIAGRO), as temperaturas médias diárias para o mês de julho são de $10,8{ }^{\circ} \mathrm{C}$, com média das mínimas de $-2,7^{\circ} \mathrm{C}$ para o mesmo mês. Por estes e outros motivos, Campos do Jordão é caracterizada como uma estância turística desde 1978, conforme Pivott (2006) -, por atender aos requisitos da Lei Estadual $n^{\circ}$ 10.426, de 8 de dezembro de 1971 (ALESP, 2013). Há diversas denominações a partir da classificação de estância turística para Campos do Jordão, como climática (SÃO PAULO, 2013a), hidromineral (SÃO PAULO, 2013b) ou somente turística, a qual é corroborada na análise de Pivott (2006). Dentro os inúmeros atrativos existentes no município, destaca-se o PECJ como um dos principais atrativos de natureza. O PECJ também é conhecido na região com o nome de Horto Florestal.

Partindo destas considerações iniciais, o presente artigo objetiva apresentar as principais características do Programa de Uso Público do PECJ, produzido na revisão do Plano de Manejo da UC (2012-2013), com a finalidade específica de: a) caracterizar a situação atual da visitação pública na $\mathrm{UC}$; b) identificar os potenciais de visitação pública ainda não aproveitados no PECJ; e c) analisar, planejar, (re) direcionar e indicar métodos de monitoramento da visitação para os diferentes tipos de públicos, a fim de valorizar seu patrimônio natural e cultural e incentivar sua conservação.

Para tanto, foram desenvolvidas análises com base em um diagnóstico da visitação pública fornecido pela gestão do PECJ e complementado em campo com entrevistas não estruturadas e observações diretas para verificação de aspectos específicos que contribuíram para a delimitação do programa. Também foi feita uma análise dos dados obtidos, por meio de técnicas estatísticas de regressão para os fluxos de visitação. Posteriormente, elaborou-se uma matriz SWOT para uma análise estratégica do PECJ, considerando seus ambientes externo (público-alvo, mercado, ambiente e riscos) e interno (cf. AAKER, 2012). Estas análises permitiram a produção de diretrizes, objetivos, indicadores e linhas de ação para o Programa 
de Uso Público, aspectos estes que são usuais nos Planos de Manejo das Unidades de Conservação administradas pela Fundação Florestal - órgão da Secretaria Estadual do Meio Ambiente de São Paulo que é responsável pela gestão das UCs paulistas. Tais aspectos são apresentados sumariamente neste artigo.

\section{BREVE CARACTERIZAÇÃO DO USO PÚBLICO NA ÁREA DE ESTUDO}

O PECJ possui seu uso público já consolidado, com diversos serviços sendo prestados aos visitantes. No entanto, a menor parte destes serviços se assemelha ao padrão usual de produtos ecoturísticos, como usualmente seria esperado em uma UC na categoria Parque (cf. BRASIL, 2000). São exemplos que destoam dessa perspectiva a existência de um trenzinho movido à base de combustível fóssil e as áreas para piquenique com churrasqueiras, na área de uso público. Outros serviços e infraestruturas também estão disponíveis aos visitantes, como restaurante, chocolateria e parque infantil. Estes se assemelham mais ao chamado turismo baseado na natureza (cf. EAGLES et al., 2002) do que ecoturismo. Atividades mais compatíveis com uma UC categoria Parque também estão disponíveis, como a visita ao viveiro de mudas, uma agência de ecoturismo - com passeios de arborismo e locação de bicicletas - e um centro de visitantes. Quanto aos atrativos naturais, o PECJ conta com 6 trilhas, com distâncias e níveis de dificuldade variadas, algumas temporariamente fechadas para a visitação. Destas, as trilhas dos Campos e da Cachoeira constam do programa Trilhas de São Paulo (SECRETARIA DO MEIO AMBIENTE, 2014), sendo classificadas pelos parâmetros deste programa com grau de dificuldade baixa. Além disso, o diagnóstico de oportunidades de uso público elaborado pela gestão do PECJ apontou também para novas possibilidades, como abertura de novas trilhas, prestação de outros serviços aos visitantes (e.g. lodges de montanha) e regularização da situação do estacionamento de veículos - um gargalo atual para o uso público.

\section{RESULTADOS E DISCUSSÃO}

a) Turismo em Campos de Jordão e Uso Público no Parque Estadual de Campos do Jordão

A visitação do PECJ tem como principal fator condicionante a sua inserção no município de Campos do Jordão, um dos principais destinos turísticos do Estado de São Paulo, incluído também nas políticas públicas federais de Turismo. Esta inclusão ocorre por meio de sua menção, em conjunto com Ilhabela, no programa Roteiros do Brasil (MINISTÉRIO DO TURISMO, 2013), que apresenta os principais destinos turísticos do país em função de seu nível de organização e qualidade de seus atrativos.

Campos do Jordão também é mencionado nas políticas públicas estaduais de turismo, primeiramente por meio dos roteiros da Secretaria de Turismo do Estado. O Estado de São Paulo conta com 27 roteiros temáticos, distribuídos em seu território, mas notadamente concentrados nas regiões: central, vale do Ribeira, litoral, o tradicional circuito das águas e o vale do Paraíba. Neste último, podem ser encontrados os circuitos: Cultura Caipira, Turístico 
Religioso, Vale Histórico e o da Mantiqueira, que inclui Campos do Jordão e outros municípios da região (SECRETARIA DE TURISMO, 2013a).

Além disso, as políticas públicas estaduais também fazem menção indireta ao PECJ no programa Caminha São Paulo, no qual uma das possibilidades é a Rota Franciscana Frei Galvão, a qual se divide em diversos trechos - também chamados de rotas - com nomes que fazem alusão a sentimentos e sensações humanas. O PECJ está localizado na Rota Alegria, que liga Guaratinguetá à São José dos Campos, em um total de $192 \mathrm{~km}$, percorridos à pé por caminhantes, cicloturistas e romeiros (SECRETARIA DE TURISMO, 2013b).

Não obstante a estes programas e ações serem compreendidos como pressões positivas no fluxo turístico para Campos do Jordão e, consequentemente, para o PECJ, nenhum deles faz menção à UC.

No âmbito municipal, o PECJ compõe um roteiro temático que é mencionado no guia do Campos de Jordão e Região Convention \& Visitors Bureau (CJRC \& VB, 2012). O chamado Roteiro Parque Estadual é divulgado como um roteiro de um único dia, incluindo outros atrativos locais e o PECJ.

De um modo geral, o potencial do PECJ para o uso público é subestimado nas esferas públicas federal e estadual. No âmbito municipal, os trabalhos de campo realizados em janeiro de 2013 permitiram um contato com a Secretaria de Turismo do município, que segundo informado no Centro de Informações Turísticas, não possuía material institucional próprio sobre os atrativos do município. Também não existia no local material específico do PECJ, seja produzido pela prefeitura ou pelo próprio Parque. Na ocasião foram indicados os guias produzidos por entes privados, como o Guia Castelfranchi e o guia do CJRC \& VB, o qual é citado na presente análise. Com isso, completa-se preliminarmente o ciclo analítico das políticas públicas sobre o turismo, sem a percepção direta da valorização do PECJ como um dos principais atrativos de natureza do destino.

Sobre os fluxos turísticos municipais e para o PECJ, informações que constam em São Paulo (2009) afirmam que, segundo a sua Secretaria de Turismo, o município de Campos do Jordão recebe aproximadamente 1,3 milhões de turistas no inverno. Este valor não é exato, considerando a dificuldade de se mensurar fluxos turísticos em destinos multi entradas e com opções de hospedagem que incluem casas de parentes e relativos (cf. SEATON; PALMER, 1997; WÖBER, 2000). No caso do PECJ, o controle em suas portarias é possível. A Figura 1 traz os dados de visitação da UC no período 1999-2010, fornecidos pela gestão. 
Figura 1. Visitação anual no PECJ.

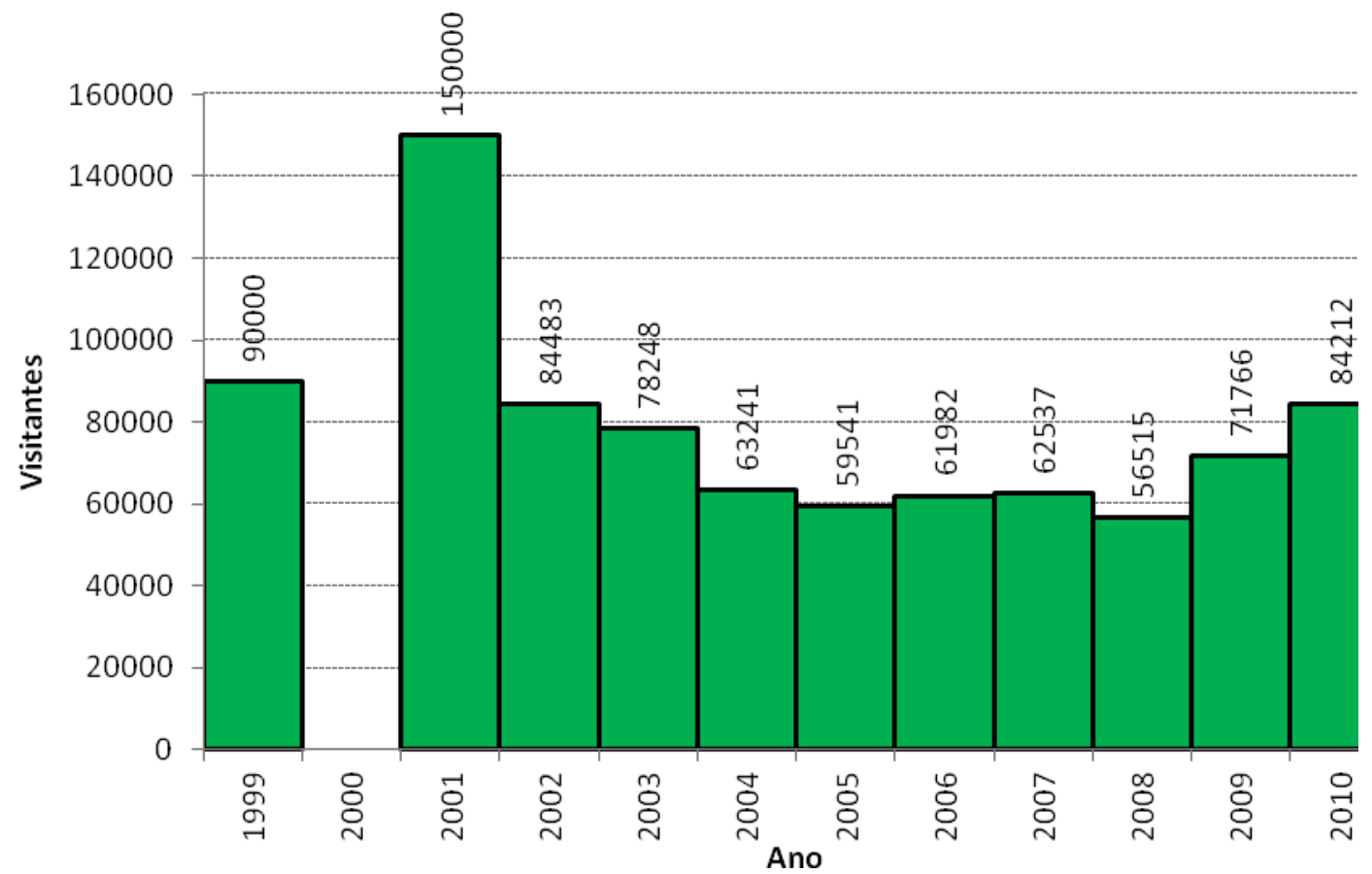

Fonte de dados: Gestão do PECJ.

A inexistência de dados exatos sobre do total de turistas em Campos do Jordão não permite uma aferição precisa sobre a participação do atrativo PECJ no mercado turístico local. Embora parte dos visitantes possa ser composta pelos próprios munícipes, sob a ótica do volume de visitação esta questão é indiferente, pois os recursos e os limites de visitação devem ser balizados pelos tipos de público, e não especificamente por sua origem. Exceções devem ser feitas acerca das possibilidades de aproximação da comunidade local com as UCs, por meio de programas de incentivo e até mesmo redução de preços nos ingressos. No entanto, estas questões não interferem na análise histórica dos fluxos de visitação.

A análise preliminar dos dados de visitação com vistas ao ciclo de vida das destinações turísticas (BUTLER, 1980) foi feita com o uso de dois procedimentos de análise de tendência: a suavização por média móvel e a regressão linear (Figura 2). 
Figura 2. Análises preliminares das séries de dados de visitação por média móvel (linha verde) e regressão linear (linha vermelha).

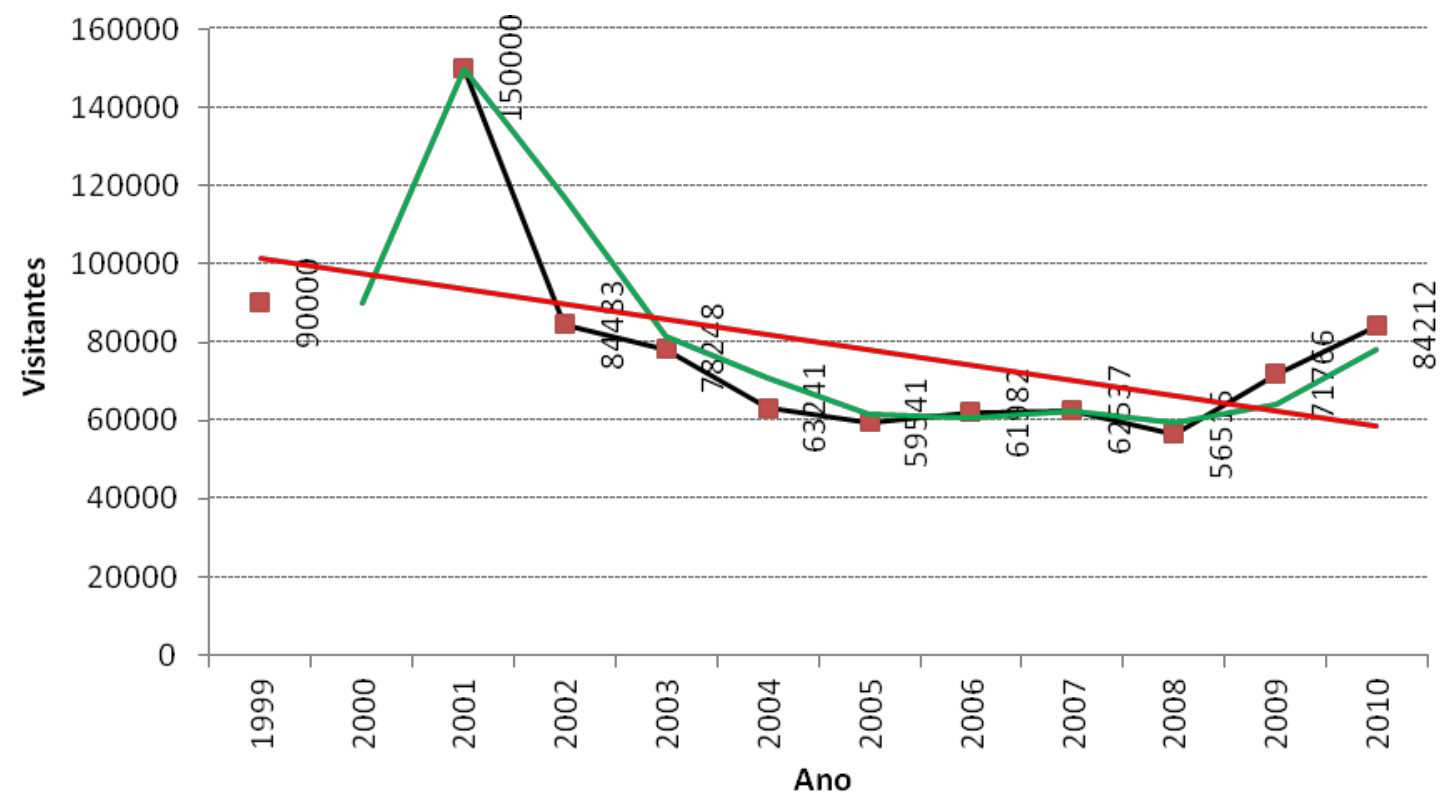

-Visitação anual — 2 por Média Móvel (Visitação anual) —Linear (Visitação anual)

Embora a série de dados disponível não seja extensa (menos de 15 anos) ou detalhada o suficiente para uma análise mais apurada (fluxo apenas anual, quando o ideal seria mensal), e com ausência de dados para o ano de 2000, algumas considerações podem ser obtidas a partir da Fig. 2. Analisando inicialmente pela regressão linear, observa-se uma tendência de declínio da visitação, o que se suporta pela inclinação da reta e pelo respectivo coeficiente $\beta$ de $\mathrm{x}$, igual a 3887,6 negativos. Todavia, deve-se considerar que os valores absolutos de 90.000 e 150.000 visitantes dos anos de 1999 e 2001 (que por se tratarem de números exatos, levam a intuir que não são frutos da mesma metodologia de contagem dos demais anos) interferem drasticamente neste cenário. Sem estes, o coeficiente $\beta$ de $x$ se reduz significativamente, apontando para uma tendência próxima à estagnação.

Por outro lado, a média móvel permite um detalhamento maior da curva de tendência de visitação do PECJ, apresentando, conforme as fases definidas por Butler (1980), os seguintes períodos do ciclo de vida de um produto turístico: declínio acentuado (1999-2005); estagnação (2005-2008); e revitalização (2008-2010). Todavia, as informações existentes até o fechamento deste artigo não permitem afirmar, com precisão, se estas variações são fruto de ações da gestão do PECJ ou do destino Campos do Jordão. Esta análise é importante, para verificar quais as ações, tanto do PECJ quanto de Campos do Jordão, podem gerar interferências no fluxo de visitantes da UC, permitindo a elaboração de linhas de ação com estratégias focadas na redução dos extremos de sazonalidade - para os quais a UC não está preparada - e também no declínio da visitação do PECJ. 
Além disso, para o período entre 2009 e setembro de 2011 foram disponibilizados dados mensais de visitação, que permitem compreender a curva sazonal do PECJ (Figura 3).

Figura 3. Dados mensais de visitação no período entre janeiro/2009 e setembro/2011, acrescidos da média mensal de visitantes e da curva de tendência polinomial de $6^{\mathrm{a}}$ ordem.



Conforme ilustrado na Fig. 3, notam-se dois extremos de visitação no PECJ: um período de acentuada baixa na visitação (março) e o extremo da alta temporada, no mês de julho. A curva de tendência polinomial evidencia de forma suave esta variação, contribuindo para a interpretação visual da sazonalidade na UC. Esta constatação é importante para subsidiar as políticas de recursos humanos dos prestadores de serviços, que precisam concentrar esforços em função do aumento na demanda. Outro aspecto a ser considerado é a provável necessidade de diversificação de atrativos nesta época, para desconcentrar os visitantes da área atual de uso público do PECJ.

b) Matriz estratégica de análise SWOT para o Parque Estadual de Campos do Jordão

Com base na análise realizada e apresentada nas subseções anteriores, foi elaborada uma matriz estratégica SWOT para o PECJ. As premissas apontadas na matriz foram classificadas no âmbito das forças impulsoras e prejudiciais para atingir os objetivos de Uso Público do PECJ.

Com base no Quadro 1, alguns elementos são destacados para demonstrar os aspectos mais evidentes das forças impulsoras e contrárias ou prejudiciais ao Uso Público no PECJ. Sobre as forças impulsoras, a inserção em um destino consolidado - Campos do Jordão contribui para a diminuição da curva sazonal do PECJ, fazendo com que haja visitação em todo o ano, como também já ilustrado na Figura 3. Todavia, o PECJ é refém do tipo de público que frequenta Campos do Jordão, que é mais focado em um turismo gastronômico e de luxo, e não necessariamente em um perfil de Ecoturismo ou Turismo Sustentável. Isto foi perceptível nas visitas de campo, onde empiricamente se observou o padrão de visitantes na 
zona de uso do Parque, em sua maioria composto por pessoas com atitudes e vestimentas de áreas urbanas. Aparentemente, o que estes visitantes buscam é um momento de lazer diurno, tal como uma caminhada em um Parque urbano - um turismo baseado na natureza (cf. EAGLES et al., 2002), onde podem colocar as conversas em dia e fazer planos para as atividades noturnas, que são o ponto alto do turismo em Campos do Jordão. Raros foram os grupos observados com perfil de ecoturistas, desenvolvendo atividades mais focadas efetivamente na natureza do PECJ. No entanto, cabe ressaltar que se trata de uma das UCs mais visitadas no Estado de São Paulo fora da Capital, com totais anuais muito acima da média das demais UCs paulistas (e.g. Parque Estadual Turístico do Alto Ribeira - PETAR, com média anual de 40.000 visitantes).

Quadro 1. Matriz estratégica SWOT para o uso público no PECJ.

\begin{tabular}{|c|c|c|}
\hline & $\begin{array}{c}\text { Forças favoráveis ou benéficas ao Uso } \\
\text { Público }\end{array}$ & $\begin{array}{c}\text { Forças contrárias ou prejudiciais ao Uso } \\
\text { Público }\end{array}$ \\
\hline & $\begin{array}{l}\text { - Inserção em um destino turístico } \\
\text { consolidado; } \\
\text { - Boas condições relativas de acesso e } \\
\text { proximidade com o centro urbano; } \\
\text { - Áreas de uso público atual e dos } \\
\text { potenciais futuros sem grandes } \\
\text { problemas ou conflitos socioambientais. }\end{array}$ & $\begin{array}{l}\text { - Inserção inexistente/ insignificante da UC } \\
\text { nas políticas de turismo em todas as esferas } \\
\text { públicas; } \\
\text { - Refém da alta sazonalidade de um destino } \\
\text { cujo principal determinante é de ordem } \\
\text { climática; } \\
\text { - Pressão excessiva na alta temporada; } \\
\text { - Irregularidade e insuficiência de transporte } \\
\text { público coletivo para o Parque, elitizando o } \\
\text { perfil do visitante. }\end{array}$ \\
\hline & $\begin{array}{l}\text { - Uma das UCs mais visitadas do Estado } \\
\text { de São Paulo; } \\
\text { - Contexto natural (paisagem) e turístico } \\
\text { (nomes Campos do Jordão e Horto } \\
\text { Florestal) fortes: são percebidos como } \\
\text { marcas; } \\
\text { - A imagem do pinhão e seus produtos, } \\
\text { como potencial a ser mais bem } \\
\text { aproveitado no uso público; } \\
\text { - O grande potencial histórico do local, } \\
\text { com elementos ainda existentes (ex.: } \\
\text { serraria) que remetem à funcionalidade } \\
\text { original do espaço e contam sua origem } \\
\text { e trajetória; } \\
\text { - Existência de serviços e opções de lazer } \\
\text { na UC - ainda que limitados e nem } \\
\text { sempre focados na relação uso e } \\
\text { conservação. }\end{array}$ & $\begin{array}{l}\text { - Dificuldades infraestruturais básicas para o } \\
\text { UP (ex.: filas de carros no acesso em dias de } \\
\text { muito movimento; estacionamento; } \\
\text { problemas nos banheiros etc.); } \\
\text { - Atrativos e atividades no interior da UC } \\
\text { focados em serviços ao consumidor, } \\
\text { diminuindo o caráter esperado de } \\
\text { ecoturismo em Unidades de Conservação; } \\
\text { - Desconhecimento dos gargalos de visitação } \\
\text { e respectivo limite de visitantes da UC por } \\
\text { unidade de tempo; } \\
\text { - Quantidade insuficiente de funcionários } \\
\text { focados diretamente no Uso Público; } \\
\text { - Atendimento a eventuais urgências médicas } \\
\text { sem um protocolo estabelecido em vigor; } \\
\text { - Sinalização interna, que varia entre } \\
\text { inadequada, insuficiente e incompleta. }\end{array}$ \\
\hline
\end{tabular}

Fonte: Elaborado pelo autor para o Programa de Uso Público do PECJ. 
No entanto, os aspectos que mais chamaram a atenção foram as forças contrárias ou prejudiciais ao Uso Público, para as quais foram desenvolvidas medidas no Programa proposto para contorná-las e evitar maiores problemas. Desde o acesso à UC, estes problemas são sentidos pelos visitantes, como as filas para a entrada, as pessoas descendo dos carros antes da fila com o intuito de se passarem por munícipes Jordanenses e não pagar ingresso que em tese estariam chegando a pé por morarem nas imediações - até os problemas de estacionamento - tanto pela inadequação do espaço delimitado para tal até pela falta de seguro, para um serviço que é cobrado dos visitantes. Outros problemas identificados são relativos aos serviços, focados no perfil de visitantes ora mencionado, sem oferecer, assim, estímulo para outra proposta de visitação na UC, mais adequada para a categoria em que se enquadra. Por fim, embora seja muito visitado, o parque não possui infraestrutura e equipe suficientes para atender o público, nem tampouco conhece seu limite operacional de visitação. Não há nenhum estudo, nem de coeficientes de rotatividade ou outros mais elaborados de capacidade de carga - conforme sugestão de classificação de Lobo et al. (2010) - que definam a quantidade de visitantes que o parque comporta, em suas trilhas, atrativos e infraestruturas.

\section{RECOMENDAÇÕES PARA O USO PÚBLICO DO PECJ}

A construção do Programa de Uso Público para o PECJ foi realizada tendo em vista a necessidade de aproximar as práticas correntes de uso público da unidade com os preceitos mínimos, sob a ótica do ecoturismo (sensu BRASIL, 1994, por aproximação à realidade nacional) para uma área natural protegida. Esta opção conceitual foi tomada não somente para buscar atender a base legal fornecida pelo SNUC, mas também, visando aproximar a prática do Ecoturismo com as práticas correntes de lazer e de turismo em área naturais, que por vezes recebem o nome de ecoturismo, mas não se assemelham aos seus preceitos, conforme constatado por Ross e Wall (1999) e Pires (2004), entre outros. O objetivo desta proposição é conciliar os inevitáveis impactos da presença humana nos ambientes naturais com benefícios mais amplos, não somente durante a prática da atividade, mas também após sua realização. Estes benefícios devem ser mais amplos e para ambos os envolvidos - ambiente, visitados e visitantes.

Para tentar obter esta nova perspectiva, partiu-se dos seguintes pressupostos: a) a atividade de uso público precisa ser organizada, calcada em métodos de controle e direcionamento da visitação (EAGLES et al., 2002), bem como de sensibilização sobre o ambiente visitado por meio da interpretação e educação ambiental (NEIMAN, 2009); e b) as comunidades locais precisam estar envolvidas no desenvolvimento das atividades, bem como ter garantias de oportunidades de lazer dentro da UC, com possibilidades de exercer sua cidadania de forma plena (GOODWIN, 2002).

Por se tratar de um Programa de Gestão, entendeu-se também que é necessário que existam formas adequadas de verificar se as diretrizes propostas estão sendo seguidas e se os objetivos almejados estão sendo alcançados. Assim, foram desenvolvidos indicadores, compatíveis com os objetivos traçados e, sob a ótica do ecoturismo, com base nos indicadores 
sugeridos por Ross e Wall (1999) e, indiretamente, por Eagles et al. (2002). Os resultados são apresentados no Quadro 2.

Para o uso público do PECJ, foram selecionados 5 eixos fundamentais (Quadro 2), buscando sintetizar as principais necessidades observadas, mas com base em aspectos factíveis. Esta preocupação foi assumida para que uma eventual complexidade excessiva do programa proposto não servisse de justificativa para que não visse a ser implantado - aspecto infelizmente comum no âmbito dos Planos de Manejo das UCs brasileiras.

A primeira preocupação foi coma infraestrutura de visitação e a divulgação adequada da UC. Foram sugeridas ações que possam corrigir os problemas atuais, como por exemplo, o estacionamento de carros em área muito interna à UC. A divulgação, por sua vez, deve privilegiar o fortalecimento da ideia de que o PECJ é uma área natural protegida, e quais são as práticas mais adequadas de uso público para este espaço. Em seguida, foi abordado o manejo de trilhas, tanto para que haja manutenção e estudos de limites de visitação das existentes, quanto para a realização de estudos prévios antes da abertura de novas possibilidades de uso.

Quadro 2. Diretrizes, objetivos e indicadores de monitoramento do Uso Público do PECJ.

\begin{tabular}{|c|c|c|}
\hline Diretriz & Objetivos & Indicadores \\
\hline 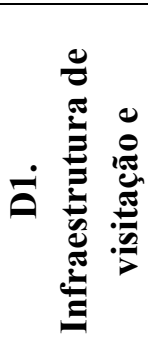 & $\begin{array}{l}\text { - Aperfeiçoar a infraestrutura } \\
\text { atual de UP; } \\
\text { - Ampliar as oportunidades de } \\
\text { uso público; } \\
\text { - Fortalecer a identidade e a } \\
\text { marca do PECJ; } \\
\text { - Divulgar de forma adequada e } \\
\text { objetiva o PECJ. }\end{array}$ & $\begin{array}{l}\text { - Reformas realizadas nas infraestruturas gerais e } \\
\text { específicas para o Uso Público; } \\
\text { - Novos atrativos, infraestruturas ou equipamentos } \\
\text { facilitadores implantados para o uso público; } \\
\text { - Marcas emblemáticas associadas ao PECJ } \\
\text { desenvolvidas e divulgadas; } \\
\text { - Folheteria, sítios na internet e APPs específicos } \\
\text { para o PECJ desenvolvidos. }\end{array}$ \\
\hline 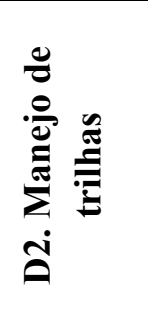 & $\begin{array}{l}\text { - Minimizar os impactos do uso } \\
\text { público sobre o ambiente; } \\
\text { - Ampliar as oportunidades de } \\
\text { uso sustentável dos recursos } \\
\text { naturais e culturais. }\end{array}$ & $\begin{array}{l}\text { - Níveis definidos e implantados de visitação para } \\
\text { os atrativos em áreas naturais, com ênfase em } \\
\text { trilhas; } \\
\text { - Periodicidade e práticas de manejo e manutenção } \\
\text { de trilhas definidas e executadas; } \\
\text { - Quantidade e qualidade de sinalização } \\
\text { interpretativa implantada. }\end{array}$ \\
\hline 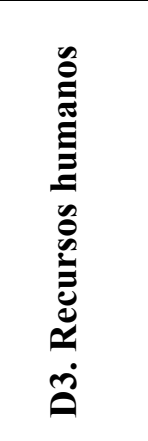 & $\begin{array}{l}\text { - Ampliar a quantidade de } \\
\text { funcionários dedicados ao UP; } \\
\text { - Manter a capacitação dos } \\
\text { funcionários de UP atualizada } \\
\text { com as tendências de } \\
\text { conservação e hospitalidade. }\end{array}$ & $\begin{array}{l}\text { - Total de funcionários contratados ou designados } \\
\text { para o Uso Público; } \\
\text { - Quantidade de programas de capacitação de } \\
\text { funcionários/ano; } \\
\text { - Quantidade de funcionários capacitados e com } \\
\text { bom desempenho nos cursos realizados/ano; } \\
\text { - Variedade de cursos oferecidos, com enfoque em } \\
\text { aspectos de uso público conservacionista, } \\
\text { hospitalidade e gestão de impactos do uso } \\
\text { público. }\end{array}$ \\
\hline
\end{tabular}




\begin{tabular}{|c|c|c|}
\hline Diretriz & Objetivos & Indicadores \\
\hline 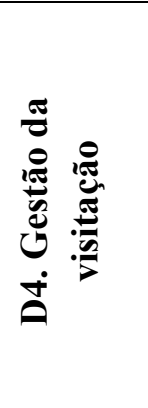 & $\begin{array}{l}\text { - Monitorar periodicamente o } \\
\text { perfil e o volume de visitantes } \\
\text { do PECJ; } \\
\text { - Identificar e sistematizar suas } \\
\text { preferências de consumo e sua } \\
\text { percepção de qualidade dos } \\
\text { serviços prestados; } \\
\text { - Monitorar os impactos do uso } \\
\text { público. }\end{array}$ & $\begin{array}{l}\text { - Perfil sazonal de visitantes do PECJ conhecido e } \\
\text { analisado; } \\
\text { - Obtenção de resultados positivos em matriz de } \\
\text { análise qualitativa das preferências de consumo e } \\
\text { percepção da qualidade nos serviços; } \\
\text { - Impactos do uso público e análise de sua } \\
\text { variação sazonal no curto e longo prazo } \\
\text { quantificados e qualificados. }\end{array}$ \\
\hline  & $\begin{array}{l}\text { - Apoiar as atividades de Uso } \\
\text { Público que podem ser } \\
\text { desenvolvidas em parceria com } \\
\text { a comunidade local; } \\
\text { - Ampliar as oportunidades de } \\
\text { uso recreativo e ecoturístico } \\
\text { para a população residente nos } \\
\text { municípios afetados pela UC. }\end{array}$ & $\begin{array}{l}\text { - Quantidade de novas oportunidades de } \\
\text { comercialização de produtos das comunidades } \\
\text { locais do entorno; } \\
\text { - Padrões estabelecidos e implantados de } \\
\text { ordenamento do uso recreativo de determinados } \\
\text { espaços na Zona de Uso Intensivo; } \\
\text { - Existência de regras diferenciadas de acesso para } \\
\text { a população residente nos municípios afetados } \\
\text { pela UC. }\end{array}$ \\
\hline
\end{tabular}

Fonte: Elaborado pelo autor para o Programa de Uso Público do PECJ (adaptado).

Os recursos humanos também foram abordados, tanto pela necessidade de existência de equipes específicas para atender ao uso público da UC quanto para estabelecer regras para o serviço de monitoria ambiental - nome dado no estado de São Paulo para a condução de visitantes. A implantação desta diretriz é imprescindível para que a gestão do uso público possa ser efetiva, com destaque para o monitoramento de seus impactos na UC.

Por fim, também foi criada uma diretriz para ressaltar a necessidade de envolvimento da comunidade local no PECJ - embora o Plano de Manejo também possua um Programa específico de Interação Socioambiental. As preocupações iniciais neste tema foram sobre as oportunidades de comercialização de produtos locais nos estabelecimentos já existentes no Parque - o que parcialmente já acontece - e a ampliação da oportunidade de visitação gratuita para os moradores de todos os municípios afetados pela UC, incluindo sua Zona de Amortecimento. Objetivando conferir um caráter prático para as diretrizes apontadas, foram desenvolvidas Linhas de Ação específicas para cada uma delas (Quadro 3).

Quadro 3. Diretrizes e suas respectivas linhas de ação para o Uso Público do PECJ. 


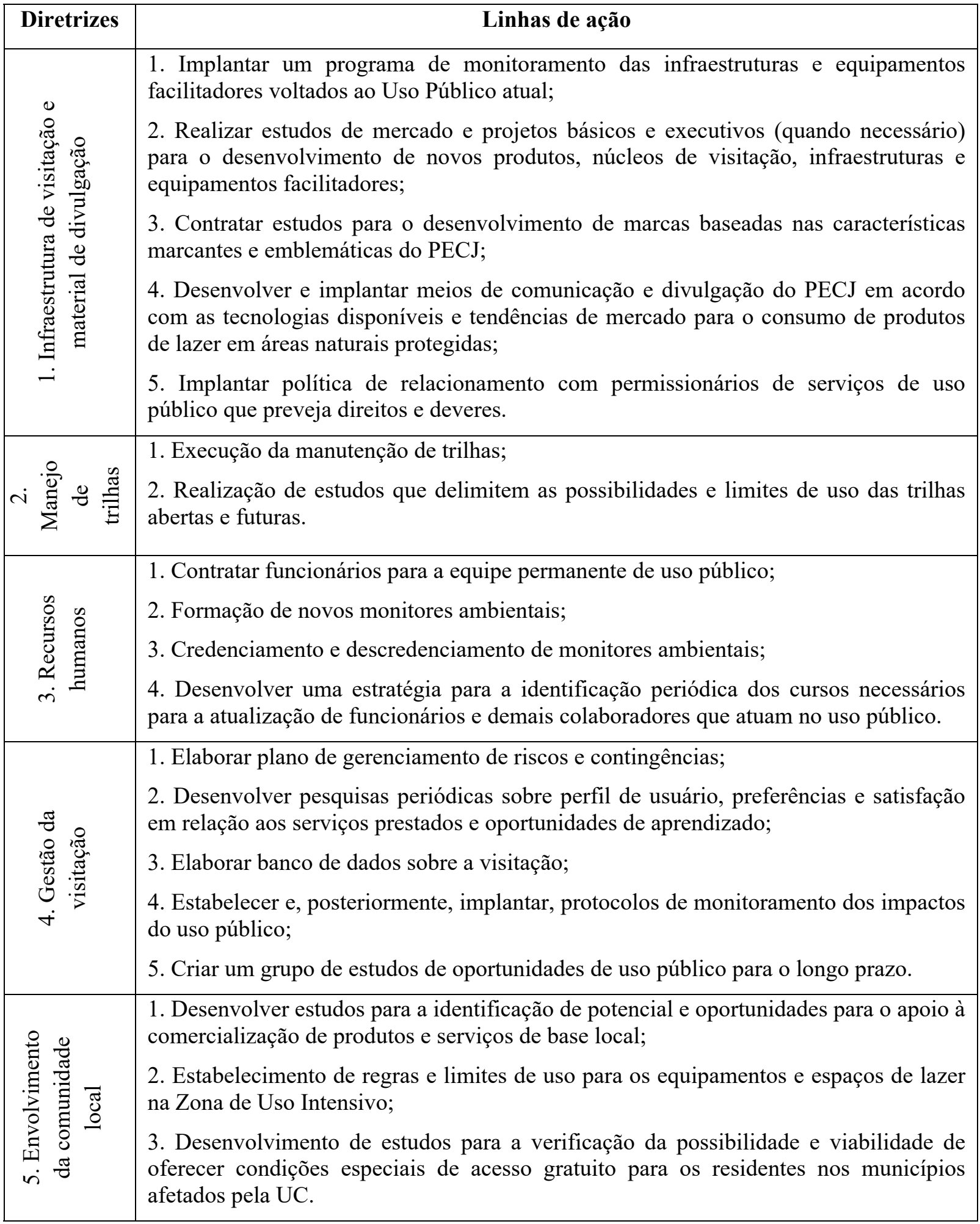

Fonte: Fundação Florestal e Ekos Brasil (2013), sintetizado e organizado pelo autor.

Ao todo, foram estipuladas 19 linhas de ação (Quadro 3), com aspectos práticos que permitem ao gestor, em qualquer tempo, identificar formas estratégicas de atuação em suas atividades cotidianas, mediante possibilidades oferecidas pelo órgão gestor - no caso, a Fundação Florestal/Secretaria do Meio Ambiente-SP. Cada uma das linhas de ação está vinculada também aos objetivos e indicadores do Quadro 2, o que permite um monitoramento 
e acompanhamento da implantação escalonada no Programa de Uso Público no PECJ. Embora no presente artigo as linhas de ação estejam sintetizadas, no Plano de Manejo da UC há um detalhamento descritivo-operacional para cada uma delas, em alguns casos com indicações até de metodologias ou mesmo padrões de execução, contribuindo para facilitar os trabalhos da gestão. Em outros, a omissão de padrões ou modelos foi proposital, pois se entende que todas estas linhas de ação devem ser debatidas no Conselho Consultivo da UC, sendo que algumas delas devem ser implantadas da forma como este julgar mais conveniente. Com isso, buscou-se fortalecer a perspectiva mais participativa na gestão do PECJ, ampliando as possibilidades de envolvimento e exercício da cidadania, sobretudo daquelas populações diretamente afetadas ou interessadas na UC.

\section{CONCLUSÕES}

O presente artigo apresentou as principais informações que permitiram a elaboração de análises e posterior desdobramento em ações executáveis para melhoria das condições de uso público do Parque Estadual de Campos do Jordão. O enfoque central do programa proposto se deu na correção de diversos problemas estruturais encontrados na UC, de ordem física, material, humana e das relações com o entorno, em diversas escalas de grandeza. O uso de referencial teórico e conceitual do Ecoturismo ensejou a necessidade de aproximar as práticas de uso público correntes nesta UC aos ideários deste segmento do turismo, bem como do Turismo Sustentável, buscando tentativas de redirecionar sua trajetória aparentemente histórica de uso derivado do perfil elitizado de turistas de inverno de Campos de Jordão. Todavia, é preciso monitorar as ações sugeridas, pois existe a possibilidade de que a alteração do perfil dos serviços e demais possibilidades existentes de uso público afugentem os visitantes atuais, sem a devida garantia de que atrairão outro público. Vale lembrar que, na maioria dos casos, os turistas que visitam regularmente Campos do Jordão estão buscando outras motivações de viagem, não se enquadrando, exatamente, nas motivações usuais do Ecoturismo ou do Turismo Sustentável. Este tema precisa ser trabalhado com os devidos cuidados, pois a perda de fluxo de visitação no PECJ pode gerar prejuízos para as comunidades atualmente envolvidas com o uso público do Parque e, até mesmo, gerar perdas para a conservação, pela redução do apoio da comunidade local.

As expectativas finais incidem sobre a preocupação com a efetiva implantação do programa, bem como do Plano de Manejo do PECJ em sua totalidade. Diversos exemplos no Estado de São Paulo, bem como no restante do território nacional, corroboram com a interpretação de que os Planos de Manejo "existem", mas infelizmente não "acontecem". Assim, é necessário que haja acompanhamento da comunidade acadêmica, dos interessados na manutenção das áreas protegidas no país e dos afetados por cada uma delas, com ações de cobrança e apoio, para que os Planos de Manejo - e seus programas, como o de Uso Público não se resumam à apenas registros no papel de possíveis intenções de solução dos problemas existentes, tal como uma lista de desejos. 


\section{REFERÊNCIAS}

AAKER, D.A. Administração estratégica de mercado. 9.ed. Porto Alegre: Bookman, 2012. $402 \mathrm{p}$.

ALESP - ASSEMBLEIA LEGISLATIVA DO ESTADO DE SÃO PAULO. Lei n $\mathbf{1 0 . 4 2 6}$, de 8 de dezembro de 1971. Dispõe sobre a criação das estâncias. Disponível em: $<$ http://www3.al.sp.gov.br/doc-e-informacao/legislacao/coletaneas-tematicas-deleis/temas?idTema=2>. Acesso em: 23.jan.2013.

BRASIL. Ministério do Meio Ambiente. Ministério da Indústria, Comércio e Turismo. IBAMA. EMBRATUR. Diretrizes para uma política nacional de ecoturismo. Brasília: EMBRATUR, 1994. 48 p.

BRASIL. Lei n. 9985 de 18 de julho de 2000. Sistema nacional de unidades de conservação. Disponível em $<$ https://www.presidencia.gov.br $>$. Acesso em: 4 dez. 2005.

BUTLER, R.W. The concept of a tourist area-cycle of evolution: implications for the management of resources. Canadian Geographic, v.14, p.5-12, 1980.

CAMPOS DE JORDÃO E REGIÃO CONVENTION \& VISITORS BUREAU. Guia oficial outono / inverno 2012. Campos do Jordão: CJRC \& VB, 2012. 74 p.

CIIAGRO - CENTRO INTEGRADO DE INFORMAÇÕES AGROMETEOROLÓGICAS. CIIAGRO online. Disponível em

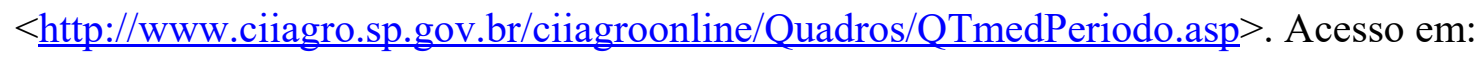
23.jan.2013.

EAGLES, P.F.J.; McCOOL, S.F.; HAYNES, C.D. Sustainable tourism in protected areas: guidelines for planning and management. Gland: IUCN, 2002. 183 p.

FENNEL. D. Ecotourism. 2.ed. London and New York: Routledge, 2003. 233 p.

FUNDAÇÃO FLORESTAL. EKOS BRASIL. Plano de manejo do Parque Estadual de Campos do Jordão. São Paulo: Fundação Florestal, 2013. p.i.

GOODWIN, H. Local community involvement in tourism around National Parks: opportunities and constrains. Current Issues in Tourism, v.5, n.3-4, p.338-360, 2002.

LOBO, H. A. S. ; PERINOTTO, J. A. J. ; BOGGIANI, P. C. . Tourist carrying capacity in caves: main trends and new methods in Brazil. In: 6th CONGRESS OF INTERNATIONAL SHOW CAVES ASSOCIATION, 2010, Liptovsky Mikulas. Proceedings. Liptovsky Mikulas: State Nature Conservance of the Slovak Repubic, 2010. v.6. p.108-115.

MINISTÉRIO DO TURISMO. São Paulo arredores. Disponível em: $<$ http://www.roteirosdobrasil.tur.br/estado_sp_saopaulo.html $>$. Acesso em: 21.jan.2013. 
NEIMAN, Z. Estudo sobre as motivações para o comportamento pró-ambiente: o potencial transformador do contato com a natureza. Revista Brasileira de Educação Ambiental, v.4, p.206-214, 2009.

PIRES, P. dos S. Dimensões do ecoturismo. São Paulo: SENAC, 2002. 272 p.

PIVOTT, C. O turismo e a produção social do espaço urbano: estudo sobre Campos do Jordão, SP. 2006. 346 p. Dissertação de Mestrado (Pós-graduação em Planejamento Urbano e Regional) - Universidade do Vale do Paraíba. 2006.

ROSS, S.; WALL, G. Ecotourism: towards congruence between theory and practice. Tourism Management, v.20, p.123-132, 1999.

SÃO PAULO (Estado). SECRETARIA DE TURISMO. DEPARTAMENTO DE APOIO AO DESENVOLVIMENTO DAS ESTÂNCIAS (DADE). Estâncias. Disponível em:

$<$ http://www.turismo.sp.gov.br/dade/estancias.html>. Acesso em: 23.jan.2013a.

SÃO PAULO (Estado). Estâncias hidrominerais. Disponível em:

$<$ http://www.saopaulo.sp.gov.br/conhecasp/turismo_estancias-hidrominerais $>$. Acesso em: 23.jan.2013b.

\section{SECRETARIA DO MEIO AMBIENTE DO ESTADO DE SÃO PAULO. Programa trilhas}

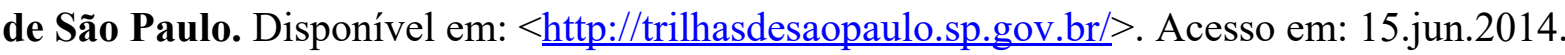

SEATON, A.V.; PALMER, C. Understanding VFR tourism behavior: the first five years of the United Kingdom tourism survey. Tourism Management, v.18, n.6, p.345-355, 1997.

SECRETARIA DE TURISMO. Circuitos turísticos. Disponível em:

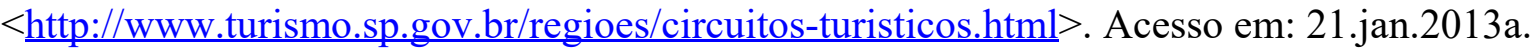

SECRETARIA DE TURISMO. Rota franciscana Frei Galvão. Disponível em:

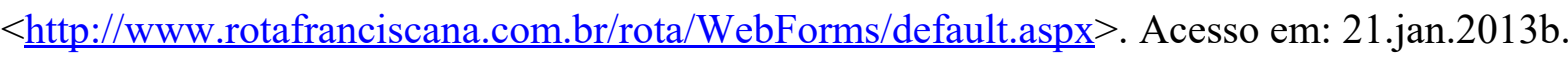

WÖBER K.W. Standardizing city tourism statistics. Annals of Tourism Research, v.27, n.1, p. 51-68, 2000. 